\title{
LOCAL ADAPTATION OF AN ANURAN AMPHIBIAN TO OSMOTICALLY STRESSFUL ENVIRONMENTS
}

\author{
Ivan Gomez-Mestre ${ }^{1}$ And Miguel Tejedo \\ Departamento de Biología Evolutiva, Estación Biológica de Doñana, Consejo Superior de Investigaciones Científicas, \\ Avenida Maria Luisa s/n, Pabellon del Perú, 41013 Sevilla, Spain
}

\begin{abstract}
Water salinity is an intense physiological stress for amphibians. However, some species, such as Bufo calamita, breed in both brackish and freshwater environments. Because selection under environmentally stressful conditions can promote local adaptation of populations, we examined the existence of geographic variation in water salinity tolerance among B. calamita populations from either fresh or brackish water ponds in Southern Spain. Comparisons were made throughout various ontogenetic stages. A combination of field transplant and common garden experiments showed that water salinity decreased survival probability of individuals in all populations, prolonged their larval period, and reduced their mass at metamorphosis. However, significant population $\times$ salinity interactions indicated that the population native to brackish water (Saline) had a higher salinity tolerance than the freshwater populations, suggesting local adaptation. Saline individuals transplanted to freshwater environments showed similar survival probabilities, length of larval period, and mass at metamorphosis than those native to freshwater. This indicates that increased tolerance to osmotic stress does not imply a loss of performance in freshwater, at least during the larval and juvenile phases. Despite the adaptive process apparently undergone by Saline, all populations still shared the same upper limit of embryonic stress tolerance (around $10 \mathrm{~g} / \mathrm{l}$ ), defining a window of salinity range within which selection can act. Significant differences in embryonic and larval survival in brackish water among sibships for all populations suggest the existence of a genetic basis for the osmotic tolerance.
\end{abstract}

Key words._Bufo calamita, common garden, geographic variation, local adaptation, salinity, stress, transplant experiments.

Organisms usually show high levels of variability and diversity among populations or demes across different ecological conditions (Mayr 1963; Futuyma 1998). This geographic variation provides the opportunity to study factors causing divergence and differentiation across populations, which may ultimately lead to new species formation (Endler 1977; Foster and Endler 1999). Specifically, the comparison of populations exposed to environments generating different selection regimes allows the exploration of the extent to which selective pressures result in adaptive responses and the geographic scale at which these phenomena take place. Environmental heterogeneity tends to increase the phenotypic plasticity of traits (when populations exchange migrants), with phenotypes optimized to the particular conditions on each environment (Rawson and Hilbish 1991; Sultan and Spencer 2002). However, when migration is restricted, selection under extreme conditions tends to favor local adaptation over plasticity (Pigliucci 2001). Differences in mean phenotype among populations can be considered adaptive if they have a genetic basis, and they confer fitness advantage in a given environment (Endler 1986; Sinervo and Basolo 1996). Distinction between genetic variation and environmentally induced phenotypic variation is best made using reciprocal transplant and common garden experiments (Berven et al. 1979; Antonovics and Primack 1982; Berven 1982a,b; Schmidt and Levin 1985; Trexler and Travis 1990; Reznick and Travis 1996). These approaches can identify sources of phenotypic variation attributable to local environment, population of origin, and their interaction. The first term quantifies the overall degree of phenotypic plasticity, whereas the second term describes

${ }^{1}$ Present address: Department of Biology, Boston University, 5 Cummington Street, Boston, Massachusetts 02215; E-mail: igmestre@ bu.edu. the genetic basis of the trait (Reznick and Travis 1996). The interaction term, if significant, is indicative of genetic divergence in respect to environments in question (Noordwijk 1989; Stearns 1992; Schlichting and Pigliucci 1998) and may imply local adaptation (Via 1984; Van Noordwijk 1989; Schlichting and Pigliucci 1998; Alonso et al. 2001). Some models of adaptation to heterogeneous environments predict that adaptation to a particular set of environmental conditions implies loss of fitness under a different set of environmental conditions (Huey and Slatkin 1976; Lynch and Gabriel 1987; Pease et al. 1989). Consequently, transplant and common garden experiments also allow testing this hypothesis of existence of antagonistic pleiotropic effects among alleles selected for in a different environment (Lenski and Bennett 1993; Hoffmann and Watson 1993).

In this paper, we report a study on geographic variation in tolerance of embryonic and larval natterjack toad (Bufo calamita) to osmotic stress experienced in brackish water ponds, using a combined approach of transplant and common garden experiments. Water salinity is an environmental stressor for amphibians due to their poor osmoregulatory ability (Boutilier et al. 1992). Consequently, the majority of amphibian species avoid inhabiting and breeding in saline and brackish environments (Balinsky 1981). However, a few species have populations capable of breeding in water bodies of varying salinity. One such species is B. calamita (Balinsky 1981; Beebee 1985; Sinsch et al. 1992; Gomez-Mestre and Tejedo 2002). Bufo calamita is widely distributed throughout continental Spain, in a large variety of habitats (Tejedo and Reques 1997) that include several brackish ponds in central and southern Spain (Tejedo and Reques, unpubl. data). The aim of this study was to analyze whether brackish environments effectively imposed a selective pressure on B. calamita 
life-history traits by quantifying the degree of variation in salinity tolerance within and among populations. The main predictions tested were: (1) the brackish environment constitutes a selective pressure for the aquatic phases of $B$. calamita, and (2) if adaptation has occurred, populations of $B$. calamita native to brackish water conditions should exhibit higher osmotic stress tolerance than those native to freshwater conditions. Furthermore, we expected to find that genotypes adapted to a brackish environment would be counterselected in freshwater.

\section{Materials and Methods}

Bufo calamita is an explosive breeder; most reproduction takes place within the first few weeks after strong rainfall from mid-January to mid-May, with some minor reproductive peaks corresponding to rainfall episodes later in the season (Tejedo and Reques 1997). This results in synchronic breeding among several populations, as long as rainfall is abundant and localities do not differ too much in temperature. In early April 2000, several populations of B. calamita began to breed almost synchronously in southern Spain and four populations were selected for the study. Three of them were from freshwater environments (Fresh 1, 2, and 3) and one from a brackish pond (Saline). The environment of Fresh 1 is a series of temporary shallow ponds on sandy soil surrounded by pine woods at the Parque Natural del Entorno de Doñana (Huelva province, Spain). Fresh 2 (Toba population) breeds in a mosaic of small ponds in a grassland plain over granitic ground in Sierra Morena (Córdoba province). Fresh 3 breeds in cattle ponds and in a narrow, low-current stream on granitic ground in the Sierra Norte de Sevilla (Sevilla province). The Saline population breeds in Laguna del Taraje, a shallow and temporary brackish lake, with very little vegetation around its shores and located in a depression amid olive tree cultivation. The bed of the lake is composed of clays and haline quaternary sediments, and its water is rich in sodium chloride, also containing sulfates and magnesium. Its salinity ranges from 0.2 to $22 \mathrm{~g} / \mathrm{l}$, depending on the amount and distribution of rainfall, and it increases steeply as the pond dries up.

Fresh 3 bred slightly earlier and was sampled a week before the clutches from the other three populations could be gathered. Several clutches were sampled from each population, carefully removing a string of around 500 eggs from each clutch. Embryos were brought to the laboratory where the samples were subdivided in plastic trays filled with shallow dechlorinated tap water. A random sample of 10 eggs from each clutch in each population was measured using a scaled scope ocular. Room temperature was kept roughly constant (range $20-24^{\circ} \mathrm{C}$ ) and the photoperiod followed a 12:12 cycle.

\section{Common Garden Experiments on Salt Tolerance in Embryonic and Early Larval Stages}

\section{Lethal concentration 50\% experiment}

Salinity tolerance limits for the different populations were studied using a classical toxicity test design in which a doseresponse relation between water salinity and mortality of batches of eggs was analyzed. The concentration at which a
50\% mortality occurs, LC50 (Sparks 2000), was used to compare osmotic stress tolerance among populations.

A water salinity gradient was set up using separate petri dishes. In addition to a freshwater control (dechlorinated tap water), saline water collected during the summer at the brackish lake of Taraje was diluted with dechlorinated tap water to final concentrations of $2,4,6,8,10$, and $12 \mathrm{~g} / \mathrm{l}$ total dissolved solids, as measured by a conductivity meter (OMEGA, Model CDH-46; Stamford, CT). Batches of 30 eggs from five different clutches from each population were randomly assigned to each treatment, so that a total of five replicates of the gradient per population were obtained. Censuses were taken at 48, 72, and $96 \mathrm{~h}$ after the exposure of the embryos to the gradient, and dead embryos were removed from the dishes to prevent oxygen depletion. Mortality was recorded at each census. Embryos from all four populations were at Gosner developmental stages 10-11 (Gosner 1960) at the beginning of the experiment.

Data were analyzed by nonlinear regression between mortality and "dose" (salinity; Sokal and Rohlf 1995; Sparks 2000), fitting an exponential model to the observations. Mortality was calculated as the ratio between dead and initial number of embryos, and LC50 values were derived from the regression equation. Homogeneity of slopes among the fitted models for each population was determined using an analysis of covariance (ANCOVA). Analyses were performed using the Statistica software package (StatSoft 1999).

\section{Embryonic common garden}

A second experiment was designed to test for differential tolerance among populations when exposed to sublethal water salinity throughout the entire embryonic phase and early larval phase (until Gosner stage 25). Three levels of water salinity were used in this experiment: a freshwater control, 6 $\mathrm{g} / \mathrm{l}$ and $8 \mathrm{~g} / \mathrm{l}$, derived as described for the previous experiment. Embryos derived from nine different clutches (including the five clutches used in the previous experiment) from each of the four populations were used in this experiment (four populations $\times$ nine clutches $\times$ three salinity treatments) and replicated six times in a randomized block design. String segments of 20 eggs per replicate from each clutch and population were randomly assigned to treatment. The only exception was for the Fresh 2 population, for which only six clutches could be found, and it was therefore replicated nine times instead. Survival, developmental rate (measured as number of days until Gosner stage 25), and size at Gosner stage 25 were the main response variables measured. Survival of the embryos was analyzed with a generalized linear mixed model for binary data ( $x$ survived from $y$ initial eggs) using the GLIMMIX macro of SAS version 8.00 (SAS Institute 1999). The goodness of fit of the model was assessed by the relative change in deviance with respect to the deviance of the null model. The model was checked for overdispersion calculating the ratio of the model deviance to the degrees of freedom. Number of days elapsed until Gosner stage 25 and weight at metamorphosis were log-transformed and analyzed as a mixed-model nested ANOVA using SAS version 8.00 (SAS Institute 1999). Water salinity was considered a fixed factor and population of origin, family (full sibships) nested 
within population, and experimental block were taken as random factors throughout all analyses.

\section{Larval and Juvenile Experiments}

Animals were kept in the laboratory in freshwater conditions until they reached a free feeding stage (Gosner stage 25). Tadpoles were fed rabbit chow pellets and water was renewed every third day to prevent oxygen depletion.

\section{Reciprocal transplant experiments}

Larvae from the four populations were reared in four selected natural ponds. These were: the original localities of Fresh 3 (Parque Natural de la Sierra Norte, Sevilla province) and Saline (Laguna del Taraje, Córdoba province); plus a freshwater temporary lake in the Parque Nacional de Doñana (Laguna del Zahillo, Reserva Biológica de Doñana, Huelva province), very close to the original locality of Fresh 1 but located in a protected area; and finally, a second brackish pond just $2 \mathrm{~km}$ away from Laguna del Taraje, the Laguna de los Jarales, in Córdoba province. This last pond is also a $B$. calamita breeding site (Gomez-Mestre and Tejedo 2002) and was chosen because it had a higher initial water salinity than the Laguna del Taraje and therefore provided a second brackish environment of higher osmotic stress. The transplant sites will be referred to hereafter throughout this paper as Doñana, Pedroso, Taraje, and Jarales, respectively.

This experiment had a two-way factorial design with four populations (three from freshwater ponds and one from a brackish pond) times four environments (two with freshwater and two with brackish water, the latter ones at different concentrations). Initial water salinities of the brackish ponds were $3 \mathrm{~g} / \mathrm{l}$ and $7 \mathrm{~g} / \mathrm{l}$ for Taraje and Jarales, respectively. Nevertheless, Taraje is shallower and dried earlier than Jarales, so by the end of the experiment the salinity gradient between the ponds had reversed and Taraje ended up more concentrated $(18 \mathrm{~g} / \mathrm{l})$ than Jarales $(10 \mathrm{~g} / \mathrm{l})$. Water salinity at the freshwater sites never exceeded $0.3 \mathrm{~g} / \mathrm{l}$. Two types of experiment were used to accomplish the field transplant:

Collective transplant experiment. _ Larvae of different clutches were pooled within the population and placed in enclosures that were set in randomized blocks near the shores of the ponds, the naturally preferred microhabitat of $B$. calamita. Five uncovered enclosures of $50 \times 50 \times 40 \mathrm{~cm}$ of mesh on wooden frames were set for each population in the two brackish ponds and four per population in the two freshwater ponds (five and four replicates per population in each pond). Randomly chosen groups of 15 tadpoles from each population were placed in each enclosure. The diameter of the mesh allowed free exchange with the environment but prevented the escape of tadpoles. Enclosures kept experimental individuals away from either conspecific or heterospecific competitors, but because they remained uncovered, enclosures did not prevent exposure to predation, particularly from odonate naiads. This type of enclosure provided a high degree of realism to the experiment but had the risk of losing replicates if predation was very intense.

Larvae were kept in the enclosures until forelimb emergence (Gosner stage 42), and the enclosures were checked every other day after the first metamorph appeared. Meta- morphs were removed with a dip net, put on a petri plate with wet moss and brought to the laboratory at the Estación Biológica de Doñana, where they were weighed to the nearest $0.1 \mathrm{mg}$ when they had achieved complete tail resorption (Gosner stage 46). Survival, length of the larval period (measured as the logarithm of the number of days elapsed from the beginning of the experiment until forelimb emergence) and weight at metamorphosis (log-transformed) were the variables examined. These variables were analyzed as described for the embryonic common garden experiment, except that no family factor was included because individuals from all families were pooled.

Individual transplant experiment. — To obtain an estimation of intrapopulation variation, five full-sib families from each population were randomly chosen and tadpoles were individually placed in $1 \mathrm{l}$ plastic cups, covered with a $0.5-\mathrm{mm}$ mesh lid and submerged in the pond. Ten and eight replicates per family from each population were used in the two brackish and the two freshwater ponds, respectively. The covered cups precluded competitive and predatory interactions but otherwise allowed free exchange of water and food with the pond. The cups were held by the pond or stream shore by means of a wire fence, to ensure that the tadpoles remained in their preferred microhabitat and did not sink to deeper waters. Larvae in the cups at Taraje needed to be fed rabbit chow pellets twice during the experiment because the pond was relatively oligotrophic and the space available inside the cup seemed insufficient to ensure proper natural feeding. The experiment was checked for metamorphs every other day after the first one appeared, and a similar procedure to that of the collective transplant was followed thereafter. Again, survival, duration of the larval period, and weight at metamorphosis were the response variables and analyses proceeded as described above for the embryonic common garden experiment. Comparisons among experimental sites should include not just contrasting the effect of water salinity, but also many environmental correlates and their potential interactions such as temperature range experienced, food availability, presence of parasites, etc. Thus, despite the higher degree of realism of this approach, comparison across environments should be made cautiously, although comparison of performance differences across populations within environments remains appropriate.

The fence surrounding the experimental cups by the shore of the pond at Doñana loosened and the cups containing the larvae were drawn inwards, sinking in deeper waters. This caused a massive mortality that forced its exclusion from the analyses. The design for this particular experiment thus consisted of one freshwater site and two brackish sites.

\section{Larval common garden experiment}

The same four populations from the transplant were also reared in replicated artificial pools so that direct comparisons among populations could be made under more controlled conditions than those in the field. A total of 20 plastic pools were prepared in an outdoor facility at the Instituto de Recursos Naturales y Agrobiología (Consejo Superior de Investigaciones Científicas; Seville province), three months prior to the beginning of the experiment. Pools were $1.5 \mathrm{~m}$ in 
diameter and were filled with $150 \mathrm{l}$ of either tap water or brackish water (5 g/l) brought from the Jarales pond, in Córdoba province. Pools were evenly distributed in a rectangular area with a smooth slope, and the treatment (fresh/brackish), alternatively assigned to each pool. By the time the larvae were ready to begin the experiment both treatments mimicked the conditions found in natural ponds, containing both algae and leaf litter. Several full-sib families from each population were included in the experiment to allow estimates of intrapopulation variation in salinity tolerance: eight from Fresh 1, six from Fresh 2, and nine from each of the other two (Fresh 3 and Saline). To preserve full-sib information, prevention of larvae mixing was essential and therefore, tadpoles were reared individually inside the pools using the same plastic cups as in the individual transplant experiment. The design thus corresponded with a split-plot design in which the salinity of the water was the main plot factor (with two levels, each replicated in 10 pools) and the population of origin was the subplot factor. Families where nested within populations and treated as a random factor. Each pool contained one tadpole per family per population, yielding a total of 10 replicates per family per salinity level. Once the experiment began, water was allowed to evaporate freely and pools were not refilled so that water level would drop and salinity rise as in the wild. Survival, duration of the larval period, and weight at metamorphosis were again the variables studied and analyses were performed as described above. In this case, spatial heterogeneity in the experiment was controlled by considering the random factor "pool" nested within water salinity.

\section{Juvenile experiment}

All metamorphs emerging from the larval common garden experiment were kept and raised for 60 days in the laboratory to investigate the possible existence, and persistence, of carryover effects of the larval environment experienced on the early juvenile terrestrial phase (Goater 1994; Beck and Congdon 2000). All toadlets were weighed and kept individually in petri dishes on a freshwater-soaked filter paper base. The dishes were cleaned and the paper renewed twice a week. Every two days the toadlets were fed a mixture of flightless fruit flies and tiny crickets that were sprinkled with a vitamin complex once a week. The design was a factorial one, with water salinity and population of origin as main factors, having two and four levels respectively. Survival was the main variable analyzed. However, mortality was very high for all treatments and focusing the analyses on final survival alone would fail to provide a complete picture of individual differences in the carryover effects of salinity. Consequently, information on when the toadlets died, if they did, was required in order to gain full understanding of the degree of salinity tolerance among populations. Time to death was tested by survival analysis using a Cox-regression model with the PHREG procedure from SAS version 8.00 (Allison 1995; SAS Institute 1999). A comparison of the time elapsed until death (in number of days since metamorphosis) among the toadlets deceased was also carried out using the MIXED procedure.
RESUlts

\author{
Embryonic and Early Larval Phases
}

\section{LC50 experiments}

Water salinity had a clear effect on embryonic mortality, but differences in tolerance were detected among populations. For the three freshwater populations, mortality within the first 48 hours remained low until a concentration of $10 \mathrm{~g} / \mathrm{l}$ was reached (see Fig. 1), and increased steeply afterward, fitting well an exponential model. Embryos from the Saline population suffered no mortality at all during this period, at any salinity concentration. Differences in tolerance among populations, as measured by the interaction term between population and salinity level in an ANCOVA, were highly significant $\left(F_{3,132}=11.59, P<0.001\right)$. After 72 hours of exposure, differences among populations had disappeared. LC50 values decreased as time went on, suggesting that mortality was not just restricted to the impact of the initial exposure to the osmotic stress but that water salinity had a chronic effect on continuous exposure. Embryos from the Saline population showed an initial higher tolerance to osmotic stress, but after three days of exposure the acute levels of salinity had the same effect on it as on the freshwater populations, and all ended up with LC50 values ranging from 8 to $10 \mathrm{~g} / \mathrm{l}$ (see Table 1 ).

\section{Embryonic common garden}

Below the apparent threshold of $10 \mathrm{~g} / \mathrm{l}$, water salinity caused a significant increase in mortality of the embryos compared to the freshwater controls $\left(\mathrm{y}_{2}^{2}=19.53, P<0.0001\right)$. However, the impact of salinity was not identical for the different populations, as indicated by the significant population $\times$ salinity interaction $(Z=2.04, P=0.02$; see Fig. $2)$. Sibships nested within populations also showed significant variation in survival among treatments $(Z=2.38, P<$ 0.01 ; see Fig. 3). No significant effect of the experimental blocks was detected. The change in deviance between the null model and the fitted model comprised $56 \%$ of the null model deviance. Correlations between sibship mean egg size and survival under $8 \mathrm{~g} / \mathrm{l}$ (where differences in sibship survival were largest) were only significant (and negative) in one case (Fresh 1, $r=0.223, P=0.564$; Fresh 2, $r=-0.859, P=$ 0.028 ; Fresh 3, $r=0.123, P=0.752$; Saline, $r=0.339, P$ $=0.371$ ).

No differences among populations or salinity treatments were found in the developmental rate measured as time elapsed (in days) between oviposition and achievement of the free-feeding larval stage (Gosner stage 25). Morphological abnormalities were observed only at the 8-g/l treatment. Abnormalities of the kind described for the embryos in the LC50 experiment were less frequent due to the less acute effect of this concentration, but older embryos (Gosner stage 16 onwards) and the posthatching stages showed different degrees of axial deviations (the tail bent $30-40^{\circ}$ over the ventral region) and ventral oedemas. The mean weight at Gosner stage 25 of the individuals from Saline was 33\% higher than that of the freshwater populations at the highest salinity concentration $\left(F_{1,35}=16.68, P<0.001\right.$; freshwater 

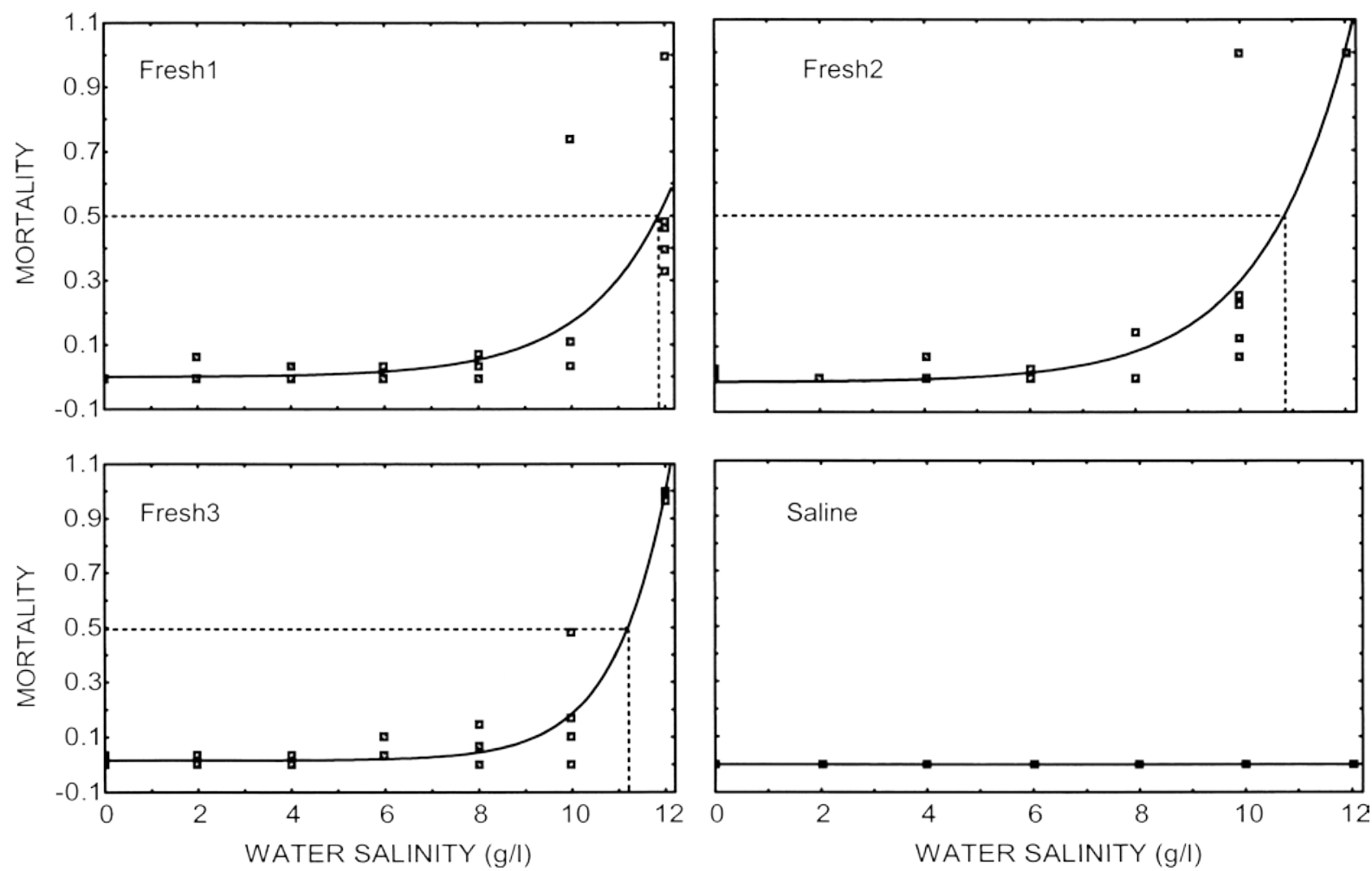

FIG. 1. Results of the LC50 experiment after the first 48 hours. Each plot corresponds to a different population. The x-axis represents the water salinity gradient ranging from freshwater to $12 \mathrm{~g} / \mathrm{l}$. The $\mathrm{y}$-axis represents mortality (as a proportion of the initial number of embryos per replicate) of the embryos at each of the stress doses. An exponential model was fit to each of the populations except for Saline, which had no variance (showed no mortality at all) and no model but a straight line could be fitted. The LC50 value for each population is graphically approximated by the dotted line depicted in each plot.

populations mean weight $=10.06 \mathrm{mg}$ ! $0.59 \mathrm{SE}$, Saline mean weight $=13.39 \mathrm{mg}$ ! $0.77 \mathrm{SE}$ ).

\section{Larval and Juvenile Experiments}

\section{Reciprocal transplant experiments}

Collective transplant experiment. - The larval environment (site) had a significant main effect on survival of the tadpoles $\left(\mathrm{y}_{3}^{2}=20.79, P=0.0001\right)$. Mean survival at the freshwater sites was $37 \%$ and $41 \%$ for Pedroso and Doñana respectively, whereas it dropped to $11 \%$ and $9 \%$ at the two brackish ponds (Jarales and Taraje, respectively). The main effect of population of origin was nonsignificant, as was site $\times$ population interaction. However, contrast analyses of the main effect of population of origin within each of the experimental sites revealed significant differences in survival among popula-

TABLE 1. LC50 averaged values (in g/l ! SE) per population at the three different censuses taken 48, 72 , and 96 hours from the beginning of the experiment. The proportion of variance explained by the fitted model to the data (from which the LC50 estimates were derived) is shown in each case (\% S). NE, nonestimable; since Saline showed no mortality within the first 48 hours of exposure, there was no salinity within the experimental gradient established causing 50\% mortality in this population. Results from the analysis of covariance are also provided.

\begin{tabular}{|c|c|c|c|c|c|c|}
\hline \multirow[b]{3}{*}{ Population } & \multicolumn{6}{|c|}{ Time elapsed } \\
\hline & \multicolumn{2}{|c|}{$48 \mathrm{~h}$} & \multicolumn{2}{|c|}{$72 \mathrm{~h}$} & \multicolumn{2}{|c|}{$96 \mathrm{~h}$} \\
\hline & LC50 & \multirow{2}{*}{$\frac{\% \mathrm{~S}}{63.2}$} & LC50 & \multirow{2}{*}{$\begin{array}{c}\% \mathrm{~S} \\
83.6\end{array}$} & LC50 & \multirow{2}{*}{$\begin{array}{c}\% \text { S } \\
79.5\end{array}$} \\
\hline Fresh 1 & $11.86 \unlhd 0.21$ & & 9.15 】 0.19 & & 8.4 】 0.47 & \\
\hline Fresh 2 & 10.84 】 0.37 & 87 & - & - & $9 】 0.4$ & 78.4 \\
\hline Fresh 3 & 11.24 】 0.23 & 96 & 10.75 】 0.3 & 93.7 & 10.4 【 0.27 & 93.9 \\
\hline \multirow[t]{2}{*}{ Saline } & $\mathrm{NE}$ & $\mathrm{NE}$ & 10.3 】 0.14 & 92.9 & $9.4 】 0.04$ & 81.8 \\
\hline & \multicolumn{2}{|c|}{$48 \mathrm{~h}$} & \multicolumn{2}{|c|}{$72 \mathrm{~h}$} & \multicolumn{2}{|c|}{$96 \mathrm{~h}$} \\
\hline Source & $F$ & $P$ & $F$ & $P$ & $F$ & $P$ \\
\hline Population & 1.92 & 0.13 & 0.18 & 0.83 & 0.14 & 0.94 \\
\hline Dose & 84.99 & $<0.0001$ & 171.9 & $<0.0001$ & 268.6 & $<0.0001$ \\
\hline Pop $\times$ dose & 11.59 & $<0.0001$ & 1.71 & 0.19 & 1.24 & 0.30 \\
\hline
\end{tabular}




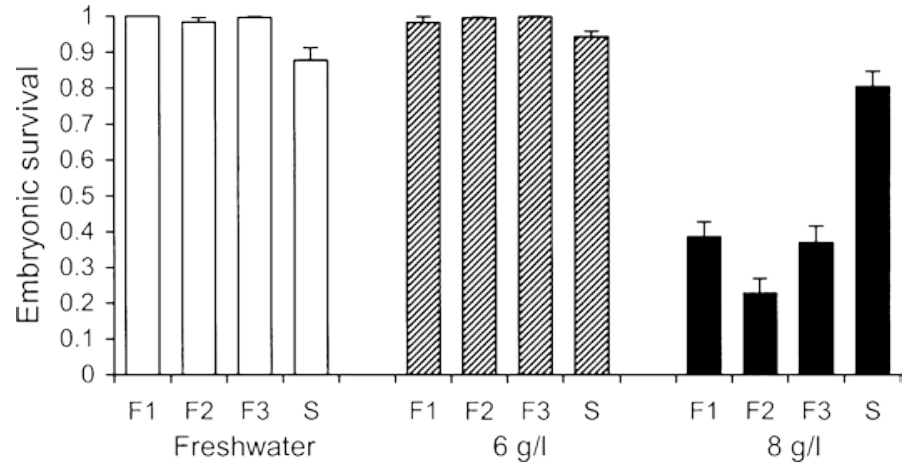

FIG. 2. Survival of the different populations along the salinity gradient in the embryonic common garden experiment. Labels F1F3 designate populations Fresh 1, Fresh 2, and Fresh 3; S designates the Saline population. The brackets on top of the bars show the standard errors.

tions under brackish conditions (Table 2). This occurred because the larvae from the Saline population showed higher survival under osmotic stressful conditions.

The length of the larval period was only affected by the main factor site $\left(F_{3,38}=59.42, P<0.0001\right)$. Tadpoles experienced a delay of about 10 days in achieving metamorphosis when they were raised in the brackish pond to which the Saline population is native (Taraje). Weight at metamorphosis was also only affected by the factor site $\left(F_{3,36}=\right.$ $6.40, P=0.001)$. Metamorphs emerging from the enclosures in Saline's native pond were the smallest, as revealed by a
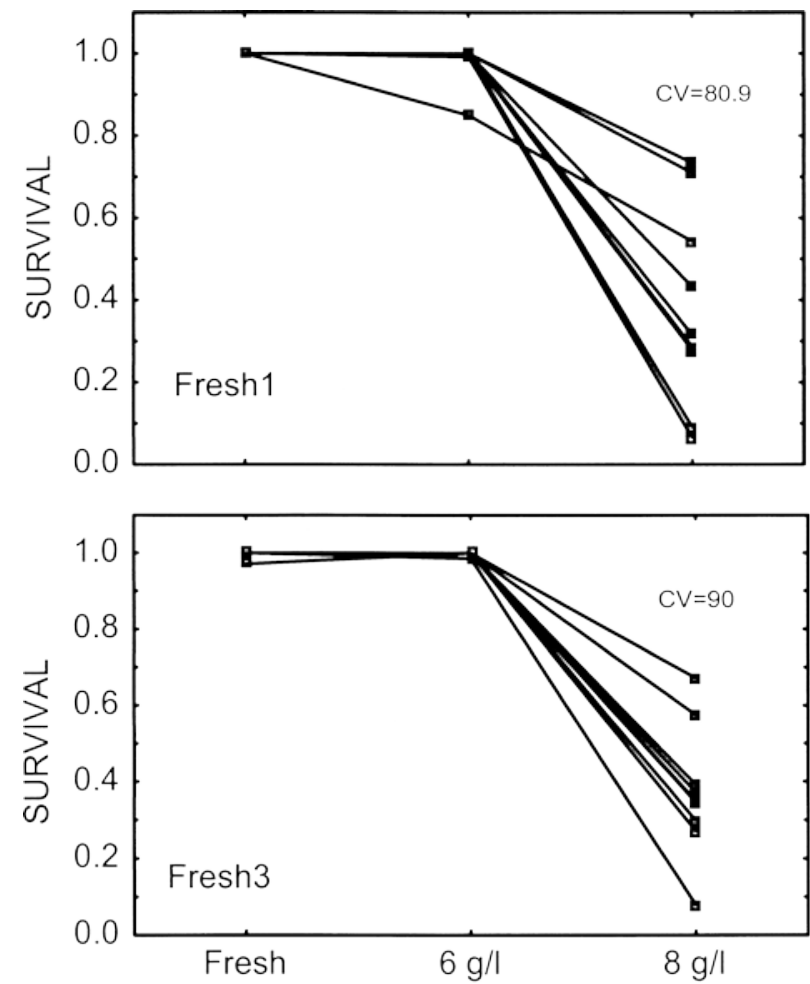

WATER SALINITY post hoc Tukey test adjusted for unbalanced designs. No differences among populations within this site could be observed.

Individual transplant experiment. - The main factor site had the greatest effect on the survival of the tadpoles $\left(y_{2}^{2}=26.30\right.$, $P<0.0001$ ), the freshwater environment being the one allowing the highest survival (see Fig. 4). The interaction between site and population was marginally nonsignificant $(Z$ $=1.61, P=0.054)$, showing a trend toward higher survival of Saline than the freshwater populations at the brackish water sites (see Fig. 4). Mortality at the brackish sites was high enough to preclude any statistical analysis on the effect of the family factor within population.

Duration of the larval period was considerably longer in brackish environments than in freshwater environments. Factor site significantly affected the date of metamorphosis of the tadpoles $\left(F_{2,6}=104.62, P<0.0001\right)$. Neither population nor the term site $\times$ population interaction were significant, perhaps as a consequence of the decreased survival of most of the freshwater populations, which decreased our statistical power. Differences among populations in the duration of the larval period could only be hinted at when tadpoles were raised in the brackish ponds. The results of contrast analysis comparing Saline versus freshwater populations at the different sites yielded: Pedroso, $F_{1,51}=0.01, P=0.943$; Jarales, $F_{1,45}=2.97, P=0.09$; Taraje, $F_{1,31}=13.76, P<0.001$. Field observations showed that by the time $30 \%$ of the Saline final metamorphs had emerged at either of the two brackish sites, 27\% of Fresh 2 and 14\% of Fresh 1 final metamorphs
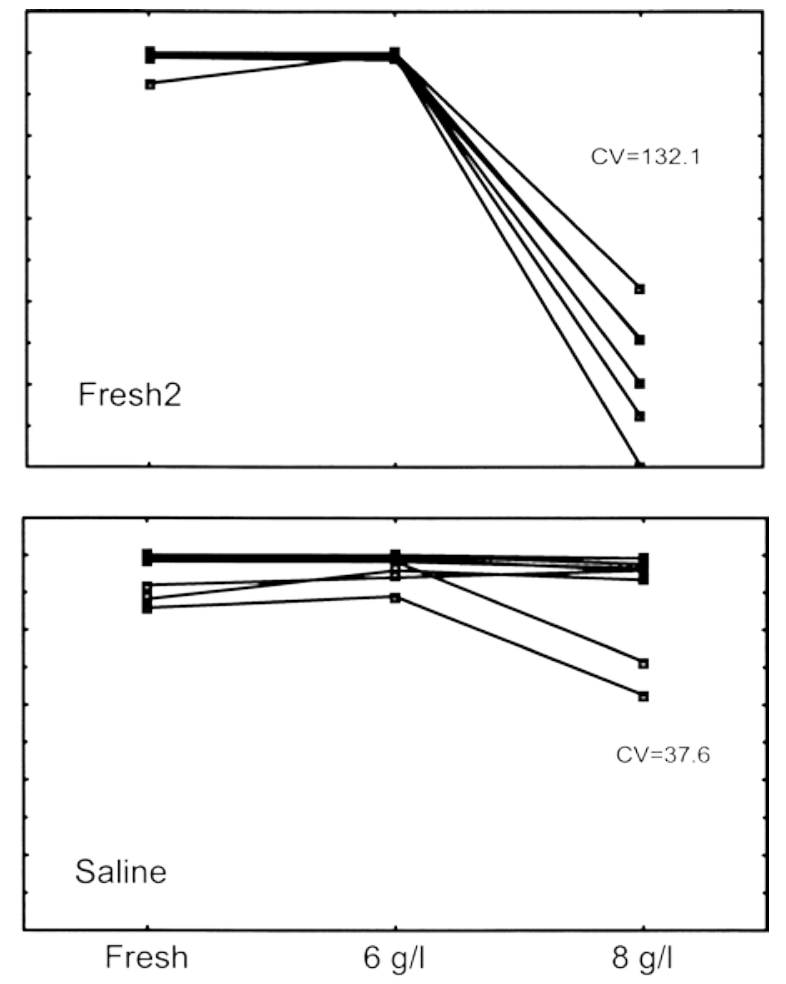

WATER SALINITY

FIG. 3. Full-sib reaction norms showing embryonic survival along the water salinity gradient in the common garden experiment. Coefficients of variation were only calculated for the highest salinity because variability at the other levels was often negligible. 
TABLE 2. Results from the collective transplant experiment showing survival differences among populations within the different field locations. Chi-square statistics of the test for population differences are provided for each environment, as well as their mean survival rate ! SE. The results show no significant survival differences among populations in the freshwater environments, only marginally significant differences at the brackish pond of Jarales, and highly significant differences at the other brackish pond, Taraje, which reached the highest salinity, although it began with a lower concentration.

\begin{tabular}{lcccccccc}
\hline \multicolumn{1}{c}{ Site } & $d f$ & $\mathrm{y}^{2}$ & $P$ & Fresh 1 & Fresh 2 & Fresh 3 & Saline \\
\hline Doñana (fresh) & 3,12 & 1.11 & 0.774 & $34.9 \%$ ! 10.3 & $49.9 \%$ ! 10.1 & $44.9 \%$ ! 19.1 & $33.3 \%$ ! 2.7 \\
Pedroso (fresh) & 3,8 & 3.05 & 0.384 & $53.3 \%$ ! 10.2 & $24.4 \%$ ! 4.4 & $39.9 \%$ ! 3.8 & $31.1 \%$ ! 18.2 \\
Jarales (brackish) & 3,16 & 6.71 & 0.0816 & $11.9 \%$ ! 1.3 & $9.3 \%$ ! 3.4 & $3.9 \%$ ! 2.7 & $20 \%$ ! 4.7 \\
Taraje (brackish) & 3,12 & 22.93 & $<0.0001$ & $4.9 \%$ ! 1.7 & $6.7 \%$ ! 2.7 & $3.3 \%$ ! 1.9 & $19.9 \%$ ! 5.4 \\
\hline
\end{tabular}

had emerged at Jarales, whereas none from freshwater populations had emerged at Taraje. Weight at metamorphosis was significantly lower in animals emerging from brackish environments $\left(F_{2,105}=5.21, P<0.01\right)$, and no effects of the population factor or the site $\times$ population interaction were detected.

\section{Common garden experiment}

Survival in the larval common garden experiment was significantly reduced by the salinity treatment $\left(\mathrm{y}^{2}=11.43, P\right.$ $<0.001)$. Neither the population factor nor its interaction with water salinity had significant effects on survival (see Table 3). Family, nested within population, yielded a statistically significant result $(Z=2.73, P<0.01)$. Coefficients of variation of population survival were calculated for each experimental environment (see Fig. 5) and were consistently higher under brackish conditions.

Neither population nor its interaction with salinity exerted a significant effect on length of the larval period. The random factor family, nested within population, significantly affected the length of the larval period ( $Z=2.65, P<0.01)$. No effect on the weight at metamorphosis of water salinity, population of origin, or the interaction term between them was detected.

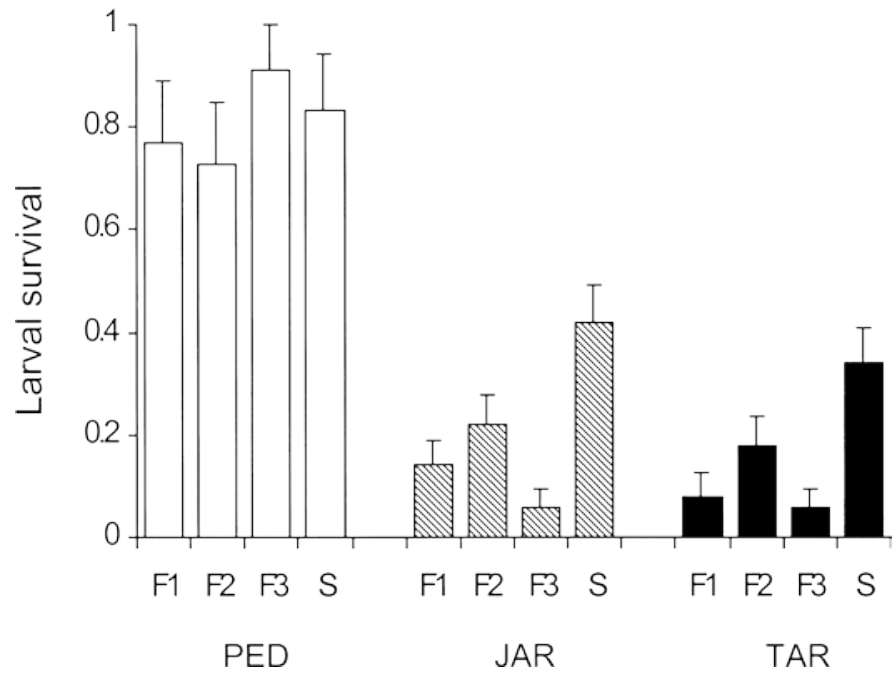

FIG. 4. Survival of the different populations at the three locations at which the individual transplant experiment was performed. The environments are, PED, Pedroso (fresh); JAR, Jarales (brackish); and TAR, Taraje (brackish). The labels F1 to F3 refer to populations Fresh 1, 2, 3; S refers to the Saline population. The brackets on top of the bars show the standard errors.

\section{Juvenile experiment}

The only factor significantly affecting the survival of metamorphs emerging from the common garden experiment was their weight at metamorphosis $\left(\mathrm{y}_{1}^{2}=20.64, P<0.0001\right)$, as revealed by the Cox-regression model. The hazard ratio for the weight of the animals censored (survivors by the end of the experiments, 60 days after metamorphosis) was 0.981. In other words, the analysis indicates that for every $1 \mathrm{mg}$ of increased weight of the newly metamorphosed toad, the hazard of death declines by an estimated $2 \%$.

\section{Discussion}

\section{Differential Embryonic Performance under a Common Upper Threshold}

Water salinity unsurprisingly constituted a selective pressure for embryonic and larval B. calamita. The osmotic stress generally caused decreased survival probability, developmental rate, and/or growth rate. The LC50 experiment indicated that some sort of tolerance threshold was attained when salinity reached about $10 \mathrm{~g} / \mathrm{l}$ (see Table 1 ), and it was so for all populations studied, even for the one native to the brackish environment. However, Saline showed a higher osmotolerance evidenced by their lack of mortality during the first two days of acute exposure (see Fig. 1). This implies that whenever the water salinity is as high as $10-11 \mathrm{~g} / \mathrm{l}$ at the time of spawning, all genotypes are likely to perish. When salinity is below that threshold, genotypes native to the brackish environment have, on average, a stronger resistance than those from freshwater populations. This higher osmotolerance of Saline was further supported by the results of the embryonic common garden experiment. Survival of the embryos decreased at the highest salinity on average $62 \%$ in the freshwater populations but only $20 \%$ in the Saline population (see Fig. 2). Because survival is highly correlated to fitness, it can be concluded that under brackish conditions, the Saline population showed a higher mean fitness than those originating from freshwater populations. Even so, the threshold found in this experiment for $B$. calamita's embryonic tolerance to water salinity is well above the one estimated by Beebee (1985) for populations in the United Kingdom, which was about $4.5 \mathrm{~g} / \mathrm{l}$ (our conversion from Beebee's data expressed as seawater \% dilution). All the populations in our study, including those from Spanish freshwater environments, showed higher tolerance limits than those detected for British B. calamita, suggesting the existence of variation in osmotic tolerance at an even broader geographic scale. 
TABLE 3. Summar y of statistical results of the generalized linear mixed models fitted to survival data obtained in the different experiments at the two life stages, embryonic and larval. $r$, random factor.

\begin{tabular}{|c|c|c|c|}
\hline Source & df & Statistic & $P$ \\
\hline Embryonic common garden (laborator y) & & \multicolumn{2}{|c|}{$N=610, \%$ deviance: 56.2} \\
\hline Salinity & 2 & $y^{2}=23.88$ & $<0.0001$ \\
\hline Population $\times$ salinity $(r)$ & 6 & $Z=2.0$ & 0.023 \\
\hline Individual reciprocal transplant (field) & & \multicolumn{2}{|c|}{$N=501, \%$ deviance: 22.3} \\
\hline Site & 2 & $y^{2}=26.30$ & $<0.0001$ \\
\hline Population $\times$ site $(r)$ & 8 & $Z=1.61$ & 0.054 \\
\hline Site Population $(r)$ & 3 & $y^{2}=20.79$ & 0.0001 \\
\hline Population $\times$ site $(r)$ & 3 & $Z=0.05$ & 0.481 \\
\hline & 9 & $Z=1.15$ & 0.126 \\
\hline Larval common garden (outdoor mesocosms) & & \multicolumn{2}{|c|}{$N=426, \%$ deviance: 59.7} \\
\hline Pool(salinity) $(r)$ & 1 & $Z=1.68$ & 0.047 \\
\hline Salinity & 1 & $y^{2}=11.43$ & $<0.001$ \\
\hline Larval environment (fresh/brackish) & 1 & $y^{2}=0.03$ & 0.874 \\
\hline Weight at metamorphosis & 1 & $y^{2}=20.64$ & $<0.001$ \\
\hline
\end{tabular}
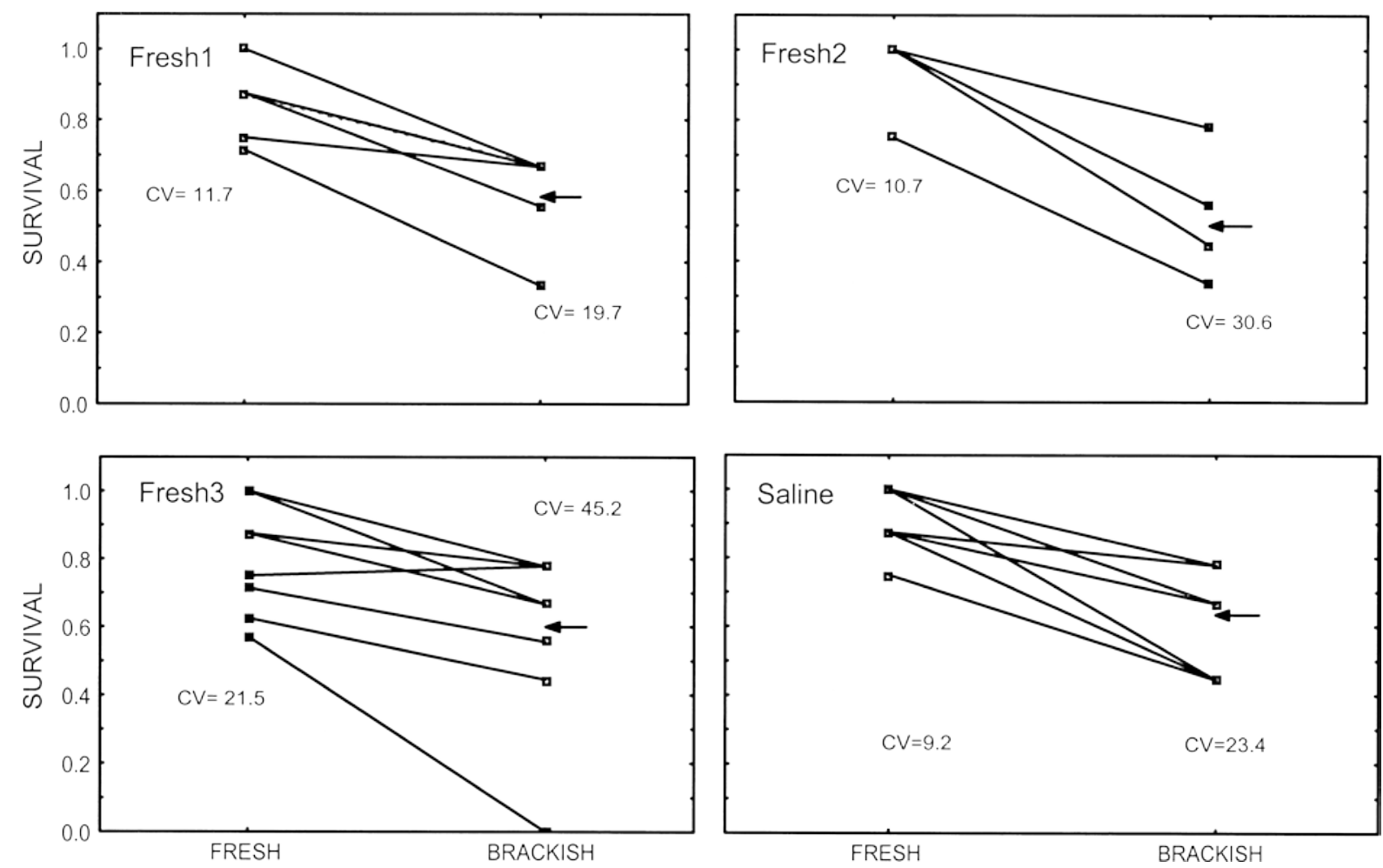

FIG. 5. Full-sib reaction norms showing larval survival at either freshwater or brackish water in the larval common garden experiment. The coefficients of variation are shown for both salinity conditions. These coefficients were consistently higher under conditions of brackish water, suggesting that differences among full sibs increase under osmotic stress. The arrows indicate the mean survival values across siblings for the brackish environment. 
In agreement with results reported on other systems evolving under stress (Lenski and Bennett 1993), the adaptive response of Saline to selection for osmotic stress tolerance did not entail a shift in the upper boundary of its osmotic niche; it shared with the freshwater populations the lethal threshold of $10-11 \mathrm{~g} / \mathrm{l}$.

\section{Differential Performance during the Larval Phase}

The patterns observed in both collective and individual experiments were very similar (see Table 3), resulting in a significant decrease in survival when the tadpoles were reared in the brackish localities as opposed to being reared in the freshwater sites. Although this decrease was significant for all populations, Saline suffered proportionally lower mortality than the freshwater populations under osmotic stress (see Table 2 and Fig. 4). The larval period was considerably extended under brackish conditions (up to 21 days in the individual transplant), yet Saline seemed to suffer a less acute retardation in reaching metamorphosis than the freshwater populations. The length of the larval period is indirectly related to fitness, because delaying metamorphosis in a temporary pond where the salinity increases steadily as the water evaporates is likely to decrease the probability of surviving.

The larval common garden experiment yielded a generally higher survival than the field experiments, but again it was observed that water salinity decreased survival. Differences in survival among populations under brackish water (revealed by the contrast analysis) were only marginally significant but followed the same trend as the previous experiments, with Saline showing a slightly lower mortality than the other populations under osmotic stress. Water salinity delayed the development of the larvae with respect to the freshwater pools as observed in the field but also to a lesser extent, and later mortality could have masked this effect in the final analyses. The lack of effect of any of the treatments on the weight at metamorphosis in the common garden experiment may explain why the salinity treatment failed to show a carryover effect on the juvenile fate during the first two months of terrestrial life (juvenile experiment). Weight at metamorphosis is the strongest factor determining the probability of survival of the juveniles and their physiological and locomotor performance efficiency in the terrestrial habitat in B. calamita (Reques and Tejedo 1997) and other amphibians (Berven and Gill 1983; Pough and Kamel 1984; Goater 1994; Newman and Dunham 1994). Weight at metamorphosis was the only variable found to determine the survival of the toadlets during the 60-day-long span after emergence from the artificial ponds of the common garden experiment. It is likely that osmotic stress of the kind met under field conditions in this study (which significantly decreased the toadlets weight) would decrease survival probability of the juvenile toads compared to individuals emerging from freshwater sites. However, it should be noted that the effect of water salinity on larval and toadlet weight might also be partially explained by different food availability and quality in brackish and freshwater ponds.

Although no formal experiment was conducted on tolerance limits for the larval phase, observations derived from both field transplant and common garden experiments suggest that it may be set at 14-16 g/l. Water salinity surpassed those values at the Taraje pond and in the artificial pools, just before drying. In both cases, all remaining larvae died within the range mentioned.

\section{Within-Population Variation}

Inferences about the evolutionary consequences of the observed differences in osmotic tolerance require knowledge of its underlying genetic basis. Differential survival among sibships within populations was found to be significant in the two experiments that allowed its analysis. These among-family differences in survival suggest the possible existence of a genetic basis for osmotic stress resistance in B. calamita. However, a full-sib design such as the one employed here precludes the distinction between additive genetic variation and maternal effects, and thus, we cannot exclude the possibility that enhanced osmotic tolerance could be totally or partially driven by maternal effects. An evident manifestation of maternal effects is egg size, which can contribute to patterns of geographic variation in amphibian life-history traits (Laugen et al. 2002). However, egg size in our system was not correlated with salinity tolerance, and eggs from Saline were either smaller or similar in size to those from the freshwater populations. Detailed quantitative genetic analysis of the heritable basis of this trait, through paternal and maternal half-sib comparisons allowing split of additive and maternal components will be presented in another paper (Tejedo et al., unpubl. ms.). Phenotypic variability was higher under brackish conditions than under freshwater conditions, as shown by the widening of the fan of reaction norms (see Figs. 3 and 5), indicating that as osmotic stress intensified, differences in tolerance among sibships were accentuated.

\section{Local Adaptation versus Phenotypic Plasticity}

Both the embryonic and the individual reciprocal transplant experiments indicated significant (marginally for the latter) genotype-by-environment interaction, suggesting local adaptation (Van Noordwijk 1989; Schlichting and Pigliucci 1998; Alonso et al. 2001). When specifically tested by contrast analysis, Saline generally showed higher survival than the freshwater populations under saline conditions. However, no population, at any ontogenetic stage, performed significantly better under brackish conditions than in freshwater, indicating that no specialization to the osmotically stressful environments has evolved in this system, despite undergoing local adaptation in salinity tolerance. Furthermore, no differences among populations were found under nonstressful, freshwater conditions, implying that no countergradient selection (Levins 1969; Conover and Schultz 1995) has occurred in the Saline population, as is sometimes observed for populations evolving under stress (Berven et al. 1979; Nicieza et al. 1994). The extent to which environmental stress modifies life-history patterns depends, among other things, on the costs of tolerance that act to reduce overall fitness. Contrary to predictions of theoretical models assuming tradeoffs in the fitness function of a given genotype across varying environments (Huey and Slatkin 1976; Lynch and Gabriel 1987; Pease et al. 1989), enhanced stress tolerance did not seem to have an associated loss of performance in the non- 
stressful environment in this system, as demonstrated also for other organisms such as bacteria (Lenski and Bennett 1993; Bennett and Lenski 1993) or fish (Nicieza et al. 1994). Osmotolerant genotypes would be unselected within freshwater populations.

Our results suggest that selection on resistance to water salinity in B. calamita is likely to be directional and apparently not constrained by trade-offs. Provided that there is enough genetic variation, population differentiation would prevail over the evolution of phenotypic plasticity because selection favors genotypes whose phenotypes under brackish conditions resemble as much as possible those exhibited in freshwater (increased relative survival and minor delays in reaching metamorphosis). In other words, selection would act only on resistance to salinity and not on the phenotypic plasticity itself. Still, the persistence of salinity-tolerant and less tolerant sibships within both brackish and freshwater populations demands explanation. Because of the apparent lack of trade-off associated to increased tolerance, genotypeby-environment interaction in this case is not likely to be a mechanism for maintaining genetic variation within populations. On the other hand, water salinity notably fluctuates both in space and time. It largely fluctuates from one year to the other depending on the amount and frequency of rainfall of the season and the preceding years. Some years, when rainfall is abundant and there has not been a long drought inertia, salinity-mediated selection on osmotic tolerance will be relaxed, and vice versa. Because the fitness of a genotype is best described by its geometric rather than its arithmetic trait mean (Gillespie 1973), genotypes that fail to survive acute but infrequent stress will have an overall fitness of zero on the long term, regardless of their mean fitness during more relaxed periods. Thus, every time salinity goes beyond the lethal embryonic threshold of 10-11 g/l at the beginning of the breeding season, all genotypes are wiped out and the entire population has no successful reproduction that year. This particularity of the system is likely to have slowed down the evolutionary rate of population divergence, and may also have been responsible for the persistence of variation in salinity tolerance within the brackish environment. Patterns of gene flow and geographic isolation among these populations need to be considered to understand the relative contribution of migration and selection to the resulting distribution of salinity-tolerant genotypes in the populations studied.

In conclusion, our results show that a significant amount of geographic variation in osmotic stress tolerance exists among B. calamita populations in southern Spain. The adaptive nature of this variation is supported by the significant population $\times$ treatment interactions detected in many of the experiments, suggesting local adaptation to salinity in the brackish water breeding population.

\section{ACKNOWLEDgments}

We thank N. Pérez, J. Hidalgo, R. Reques, and B. Estrada for their assistance in the setting up and surveillance of the experiments. C. M. Herrera, C. Schneider, J. B. Losos, J. Mërila, and two anonymous reviewers helped improve earlier versions of this manuscript. This work was supported by grant PB96-0861 from Dirección General de Investigación Cien- tífica y Técnica conceded to MT and the predoctoral grant AP97 05421411 from the Dirección General de Enseñanza Superior e Investigació n Científica to IGM. Thanks also to the Consejería de Medio Ambiente de la Junta de Andalucia and the Reserva Biológica de Doñana, for providing the corresponding permits and facilities.

\section{Literature Cited}

Allison, P. D. 1995. Survival analysis using the SAS system. A practical guide. SAS Institute, Cary, NC.

Alonso, C., K. Ruohomaki, M. Riipi, and J. Henriksson. 2001. Testing for prerequisites of local adaptation in an insect herbivore, Epirrita autumnata. Ecoscience 8:26-31.

Antonovics, J., and R. B. Primack. 1982. Experimental ecological genetics in Plantago. VI. The demography of seedling transplants of $P$. lanceolata. J. Ecol. 70:55-75.

Balinsky, J. B. 1981. Adaptation of nitrogen metabolism to hypertonic environment in Amphibia. J. Exp. Zool. 215:335-350.

Beck, C. W., and J. D. Congdon. 2000. Effects of age and size at metamorphosis on performance and metabolic rates of southern toad, Bufo terrestris, metamorphs. Funct. Ecol. 14:32-38.

Beebee, T. J. C. 1985. Salt tolerances of natterjack toad (Bufo calamita) eggs and larvae from coastal and inland populations in Britain. Herpetol. J. 1:14-16.

Bennett, A. F., and R. E. Lenski. 1993. Evolutionary adaptation to temperature. II. Thermal niches of experimental lines of Escherichia coli. Evolution 47:1-12.

Berven, K. A. 1982a. The genetic basis of altitudinal variation in the wood frog Rana sylvatica. I. An experimental analysis of life history traits. Evolution 36:962-983.

- 1982b. The genetic basis of altitudinal variation in the wood frog Rana sylvatica. II. An experimental analysis of larval development. Oecologia 52:360-369.

Berven, K. A., D. E. Gill, and S. J. Smith-Gill. 1979. Countergradient selection in the green frog, Rana clamitans. Evolution 33: 609-623.

Berven, K. A. and D. E. Gill. 1983. Interpreting geographic variation in life history traits. Am. Zool. 23:85-97.

Boutilier, R. G., D. F. Stiffler, and D. P. Toews. 1992. Exchange of respiratory gases, ions, and water in amphibious and aquatic amphibians. Pp. 81-124 in M. E. Feder and W. W. Burggren, eds. Environmental physiology of the amphibians. Univ. of Chicago Press, Chicago, IL.

Conover, D. O., and E. T. Schultz. 1995. Phenotypic similarity and the evolutionary significance of countergradient variation. Trends Ecol. Evol. 10:248-252.

Endler, J. A. 1977. Geographic variation, speciation, and clines. Princeton Univ. Press, Princeton, NJ.

- 1986. Natural selection in the wild. Princeton Univ. Press, Princeton, NJ.

Foster, S. A., and J. A. Endler. 1999. Thoughts on geographic variation in behavior. Pp. 287-307 in S. A. Foster and J. A. Endler, eds. Geographic variation in behavior. Oxford Univ. Press, Oxford, U.K.

Futuyma, D. J. 1998. Evolutionary biology. Sinauer Associates, Sunderland, MA.

Gillespie, J. H. 1973. Polymorphism in random environments. Theor. Popul. Biol. 4:193-195.

Goater, C. P. 1994. Growth and survival of postmetamorphic toads: interactions among larval history, density and parasitism. Ecology 758:2264-2274.

Gomez-Mestre, I., and M. Tejedo. 2002. Geographic variation in asymmetric competition: a case study with two larval anuran species. Ecology 83:2102-2111.

Gosner, K. L. 1960. A simplified table for staging anuran embryos and larvae with notes on identification. Herpetologica 16: 183-190.

Hoffmann, A. A., and M. Watson. 1993. Geographical variation in the acclimation responses of Drosophila to temperature extremes. Am. Nat. 142:S93-S113. 
Huey, R. B., and M. Slatkin. 1976. Cost and benefits of lizard thermoregulation. Q. Rev. Biol. 51:363-384.

Laugen, A.T., A. Laurila, and J. Merilä. 2002. Maternal and genetic contributions to geographical variation in Rana temporaria larval life-history traits. Biol. J. Linn. Soc. 76:61-70.

Lenski, R. E., and A. F. Bennett. 1993. Evolutionary response of Escherichia coli to thermal stress. Am. Nat. 142:S47-S64.

Levins, R. 1969. Thermal acclimation and heat resistance in Drosophila species. Am. Nat. 103:483-499.

Lynch, M., and W. Gabriel. 1987. Environmental tolerance. Am. Nat. 129:283-303.

Mayr, E. 1963. Animal species and evolution. Belknap Press, Cambridge, MA.

Newman, R. A., and A. E. Dunham. 1994. Size at metamorphosis and water loss in a desert anuran (Scaphiopus couchii). Copeia 2:372-381.

Nicieza, A. G., L. Reiriz, and F. Braña. 1994. Variation in digestive performance between geographically disjunct populations of Atlantic salmon: countergradient in passage time and digestion rate. Oecologia 99:243-251.

Pease, C. M., R. Lande, and J. J. Bull. 1989. A model of population growth, dispersal and evolution in a changing environment. Ecology 70:1657-1664.

Pigliucci, M. 2001. Phenotypic plasticity. Beyond nature and nurture. The Johns Hopkins Univ. Press, Baltimore, MD.

Pough, F. H., and S. Kamel. 1984. Post-metamorphic change in activity metabolism of anurans in relation to life history. Oecologia 65:138-144.

Rawson, P. D., and T. J. Hilbish. 1991. Genotype-environment interaction for juvenile growth in the hard clam Mercenaria mercenaria (L.). Evolution 45:1924-1935.

Reques, R., and M. Tejedo. 1997. Reaction norms for metamorphic traits in natterjack toads to larval density and pond duration. J. Evol. Biol. 10:829-851.

Reznick, D., and J. Travis. 1996. The empirical study of adaptation in natural populations. Pp. 243-290 in M. R. Rose and G. V. Lauder, eds. Adaptation. Academic Press, San Diego, CA.
SAS Institute. 1999. SAS/STAT software user's guide. Release 8.00. SAS Institute, Cary, NC.

Schlichting, C. D., and M. Pigliucci. 1998. Phenotypic evolution. A reaction norm perspective. Sinauer Associates, Sunderland, MA.

Schmidt, K. P., and D. A. Levin. 1985. The comparative demography of reciprocally sown populations of Phlox drummonddii Hook. I. Survivorships, fecundities, and finite rates of increase. Evolution 39:396-404.

Sinervo, B., and A. L. Basolo. 1996. Testing adaptation using phenotypic manipulations. Pp. 149-185 in M. R. Rose and G. V. Lauder, eds. Adaptation. Academic Press, San Diego, CA.

Sinsch, U., R. Seine, and N. Sherif. 1992. Seasonal changes in the tolerance of osmotic stress in natterjack toads (Bufo calamita). Comp. Biochem. Physiol. 101A:353-360.

Sokal, R. R., and F. J. Rohlf. 1995. Biometry. W. H. Freeman, New York.

Sparks, T. 2000. Statistics in ecotoxicology. John Wiley and Sons, Chichester, U.K.

StatSoft. 1999. Statistica for Windows. Ver. 5.5. Computer program manual. Tulsa, OK.

Stearns, S. 1992. The evolution of life histories. Oxford Univ. Press, New York.

Sultan, S. E., and H. G. Spencer. 2002. Metapopulation structure favors plasticity over local adaptation. Am. Nat. 160:271-283.

Tejedo, M., and R. Reques. 1997. Bufo calamita. Pp. 155-157 in J. M. Pleguezuelos, ed. Distribución y biogeografía de los anfibios y reptiles de España y Portugal. Universidad de Granada. Asociación Herpetoló gica Española, Granada, Spain.

Trexler, J., C. and J. Travis. 1990. Phenotypic plasticity in the sailfin molly, Poecilia latipinna (Pisces: Poeciliidae). I. Field experiments. Evolution 44:143-156.

Van Noordwijk, A. J. 1989. Reaction norms in genetical ecology. Bioscience 39:453-458.

Via, S. 1984. The quantitative genetics of polyphagy in an insect herbivore. I. Genotype-environment interaction in larval performance on different host plant species. Evolution 38:881-895.

Corresponding Editor: J. Merilä 